\title{
HARINA DE HÍGADO DE BOVINO EN LA ALIMENTACIÓN DE BROILERS
}

Síntesis:

Normalmente, en la elaboración de dietas para aves, se utilizan productos o subproductos que son de consumo directo para el hombre, lo que ocasiona escasez y consecuentemente, aumento de los precios de dichos ingredientes, es por esto que se vuelve necesaria la búsqueda de nuevos componentes dietéticos o materias primas que permitan satisfacer en forma barata y eficiente los requerimientos nutritivos de las aves. En base a estos principios se ha investigado en este trabajo, el comportamiento de la harina de hígado de bovino como fuente de proteínas en la alimentación de pollos broilers. Considerando lo antes mencionado, se han planteado los siguientes objetivos:

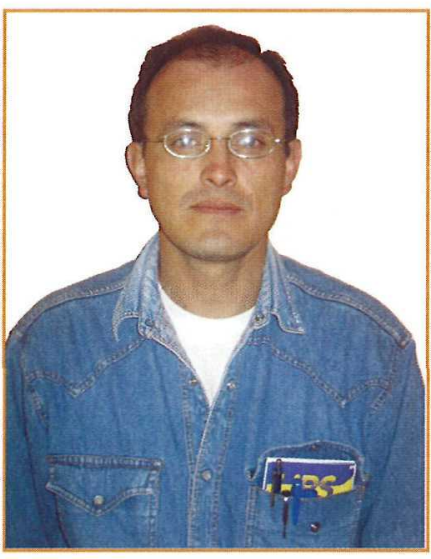

*Or. Marco Rosero

1. Determinar el efecto que produce la harina de hígado de bovino en niveles del $3 \%$, $4 \%$ y $5 \%$, en la alimentación de pollos broilers.

2. Evaluar la conversión alimenticia entre los grupos experimentales, en base al incremento de peso.

3. Evaluar económicamente los resultados mediante la determinación de los costos de producción, beneficios y rentabilidad.

\section{Nutrición animal}

La nutrición comprende una serie de operaciones y transformaciones que experimentan los alimentos digeridos, sin que intervenga en ello la voluntad del animal que los ha consumido. La nutrición incluye por consiguiente la digestión de los alimentos, la absorción de las substancias nutritivas en el intestino y las reacciones químicas más - menos complejas que resulten

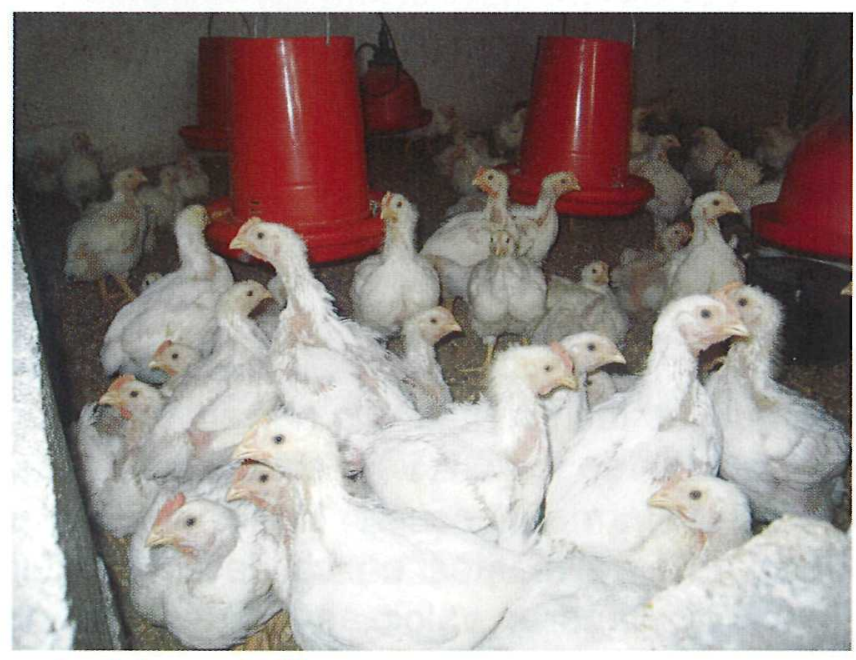
imprescindibles para la asimilación de los principios nutritivos.

\section{Las proteínas}

Las proteínas son polímeros de alto peso molecular de un grupo de monómeros de bajo peso molecular llamados aminoácidos. Durante la digestión las proteínas se desdoblan en los aminoácidos que las componen y estos pasan a la sangre, que los lleva a diferentes partes del organismo. Ahí los aminoácidos vuelven a combinarse de forma distinta a como estaban originalmente en el alimento, para formar las proteínas propias del animal.

\section{Fuentes de proteína}

Las raciones donde las proteínas proceden totalmente de los granos o de subproductos de origen vegetal dan malos resultados, debido a que estas proteínas no son de buena 
calidad y que las harinas de pescado, carne y subproductos, la leche y sus subproductos, entre otras fuentes de origen animal, son muy eficaces para corregir las deficiencias proteicas vegetales.

\section{Harina de hígado}

Los alimentos proteicos de origen animal se preparan normalmente a partir de productos animales no adecuados para el consumo humano.

La harina de hígado se prepara cociendo y moliendo los hígados de animales que no son adecuados para el consumo humano. Se muestra como una buena fuente de lisina, cistina, metionina, leucina y triptofano; y muy rica en riboflavina, colina y vitamina B12.

Composición alimenticia de la harina de hígado (7)
$\begin{array}{llll}\text { Proteína } & 65 \% & \text { Fósforo } & 1.1 \% \\ \text { Energ. Metab. } & 2860 \mathrm{Kcal} / \mathrm{kg} . & \text { Sodio } & 0.11 \% \\ \text { Grasa } & 16 \% & \text { Potasio } & 0.4 \% \\ \text { Fibra cruda } & 2 \% & \text { Manganeso } & 8 \% \\ \text { Calcio } & 07 \% & \text { Zinc } & 5 \%\end{array}$

Aminoácidos de la harina de hígado (7)

$\begin{array}{llll}\text { Arginina } & 4.1 \% & \text { Lisina } & 4.9 \% \\ \text { Cistina } & 1.0 \% & \text { Metionina } & 1.3 \% \\ \text { Glicina } & 5.6 \% & \text { Fenilalanina } & 2.9 \% \\ \text { Histidina } & 1.5 \% & \text { Treonina } & 2.6 \% \\ \text { Isoleucina } & 3.3 \% & \text { Triptofano } & 0.6 \% \\ \text { Leucina } & 5.4 \% & \text { Valina } & 4.2 \%\end{array}$

Vitaminas de la harina de hígado (4)

Vitamina A

Aneurina (B1)

Riboflavina (B2)

Niacina (PP)
$40-65 \mathrm{mg} / \mathrm{kg}$

$0.10-0.15 \mathrm{mg} / \mathrm{kg}$

4.1-6.0 $\mathrm{mg} / \mathrm{Kg}$

$25-28 \mathrm{mg} / \mathrm{Kg}$
Ácido Pantoténico $8-12 \mathrm{mg} / \mathrm{Kg}$

Biotina

$0.02 \mathrm{mg} / \mathrm{Kg}$

$3500-6000 \mathrm{mg} / \mathrm{Kg}$

Colina

Vitamina B12
$0.05-0.1 \mathrm{mg} / \mathrm{Kg}$.

Las harinas de hígado son muy utilizadas principalmente en avicultura, tanto por el suplemento proteico muy digestible y de valor biológico elevado, como por su contenido en riboflavina y otras vitaminas del complejo $\mathrm{B}$, sin contar su precioso aporte en sales de hierro y cobre.

\section{MATERIALES Y MÉTODOS}

Este estudio se llevó a cabo en el Cantón Cuenca, Parroquia Baños, en el período comprendido entre el 20 de enero al 16 de marzo de 1992. Para el trabajo de investigación, se utilizaron 600 pollitos broiler de la línea Hubart. Los pollos tenían un día de edad sin sexar, de plumaje blanco, cresta simple, buena capacidad abdominal, espalda ancha características propias de aves híbridas especializadas en la producción de carne. 
El experimento se llevó a cabo en un solo local durante todo el tiempo y el tipo de explotación fue al piso. El local presentó las siguientes características: Un cuarto con una dimensión de 6.7 metros de ancho por 9 metros de largo, con paredes de bloque y ventanas con protecciones de hierro, techos prefabricados y piso de cemento.

En el local se construyeron 12 compartimentos de 2.25 metros de largo por 2.23 metros de ancho por 1 metro de alto. El tipo de diseño aplicado fue el de bloques completos al azar con las siguientes características:

- Número total de aves

- Edad de las aves

- Línea

- Número de lotes

- Número de tratamientos

- Número de repeticiones

- Número de aves por repetición

Se emplearon 8 raciones experimentales: Cuatro para la etapa inicial con el $21 \%$ de proteina cruda y cuatro para la fase de acabado con el $18 \%$ de PC.

Las raciones de ensayo estuvieron compuestas de los siguientes ingredientes: Maíz amarillo, harina de trigo, harina de sorgo, polvillo de arroz, harina de soya, harina de pescado, harina de huesos, sal yodada, vitaminas, metionina, furidona y harina de hígado de bovino. Las raciones testigo no contenian harina de hígado.

\section{Características de los tratamientos} Tratamiento

Simbología

1
2
3
4

$\mathrm{H} 1$

$\mathrm{H} 2$

$\mathrm{H} 3$

ST

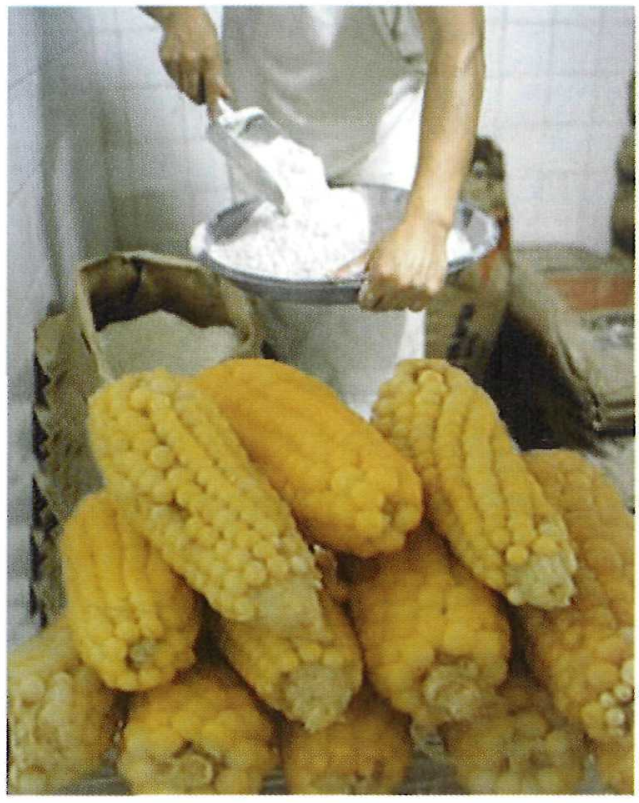

Porcentaje No. REPETICIÓN

$\begin{array}{ll}3 \% & 3 \\ 4 \% & 3 \\ 5 \% & 3 \\ \text { testigo } & 3\end{array}$


RESULTADOS

Ganancia de peso en el período 0-56 días (kg/ave)

\begin{tabular}{lccccc}
\hline \multicolumn{7}{c}{ Repetición } \\
\hline Tratamiento & I & II & III & Suma Total & XT \\
\hline H1 & 2632 & 2663 & 2642 & 7937 & 2645 \\
H2 & 2842 & 2871 & 2752 & 8465 & 2821 \\
H3 & 2571 & 2542 & 2513 & 7626 & 2542 \\
ST & 2341 & 2541 & 2442 & 7324 & 2441 \\
\hline Total rep. & 10386 & 10617 & 10349 & 31352 & 2612 \\
\hline X rep. & 2596 & 2654 & 2587 & &
\end{tabular}

ADEVA para la ganancia de peso en el período 0-56 días (kg/ave)

\begin{tabular}{lcccccc} 
FV & GL & SC & CIM & Fcal & FO5 & F01 \\
\hline Total & 11 & 0.2675 & - & - & - & $=$ \\
Tratamientos & 3 & 0.237 & 0.079 & 24.548 & 4.76 & 9.78 \\
Repeticiones & 2 & 0.01 & 0.005 & $1.63 N S$ & 5.14 & 10.92 \\
Error & 6 & 0.020 & 0.003 & & &
\end{tabular}

C.V. $=2.17 \%$

Conversión alimenticia a los 56 días

\section{Repetición}

\begin{tabular}{lccccc}
\hline Tratamiento & I & II & III & Suma Total & XT \\
\hline H1 & 2.09 & 2.10 & 2.06 & 6.25 & 2083 \\
H2 & 2.07 & 2.04 & 2.13 & 6.24 & 2080 \\
H3 & 2.12 & 2.16 & 2.18 & 6.46 & 2153 \\
ST & 2.30 & 2.12 & 2.19 & 6.61 & 2203 \\
\hline Total rep. & 8.42 & 8.42 & 8.56 & 25.56 & 2129 \\
\hline
\end{tabular}

X rep. $\quad 2145 \quad 2105 \quad 2140$


ADEVA para la conversión alimenticia a los 56 días

\begin{tabular}{lcccccc} 
FV & GL & SC & CMI & Fcal & FO5 & F01 \\
\hline Total & 11 & 0.055 & - & - & - & - \\
Tratamientos & 3 & 0.0316 & 0.0105 & $3.18 \mathrm{NS}$ & 4.76 & 9.78 \\
Repeticiones & 2 & 0.036 & 0.0018 & $0.55 \mathrm{NS}$ & 5.14 & 10.92 \\
Error & 6 & 0.0198 & 0.0035 & & &
\end{tabular}

C.V. $=2.69 \%$

\section{CONCLUSIONES}

Luego de haber obtenido los resultados del efecto que produce la adición de harina de hígado de bovino como fuente de proteína en la alimentación de pollos de carne, frente al grupo testigo, podemos concluir lo siguiente:

- La mayor ganancia de peso la obtuvo la dieta adicionada con el 4\% de harina de hígado, ya que estadísticamente se pudo comprobar que las aves alimentadas con este nivel de harina alcanzaron mayor peso promedio.

- En cuanto a la conversión alimenticia en los periodos de crecimiento y acabado (56 días), la mejor conversión la tuvo el tratamiento 4\% con 2.080, seguido por el tratamiento $3 \%$ con 2.083. Los tratamientos $5 \%$ y testigo fueron los que menor índice de conversión obtuvieron con 2.153 y 2.203 respectivamente.

\section{SUMMARY}

This study was carried out in the Cantón Cuenca, Parroquia Baños, in the period understood among January 20 at March 161992.

For the investigation work, 600 chickens broiler of the line Hubart was used. The chickens had a day of age without sexar, of white plumage, crest simple, good abdominal capacity, back wide, characteristic characteristic of hybrid birds specialized in the meat production.

The experiment was carried out in a single local during the whole time and the type of exploitation went to the floor. The local presented the following ones characteristic: A room with a dimension 6.7 meters wide for $9 \mathrm{~m}$. Of long, with block walls and windows with iron protection, roof of you burn and plastiluz and cement floor.

In the local 12 compartments of $2.25 \mathrm{~m}$ were built. Of long for $2.23 \mathrm{~m}$. Of wide for $1 \mathrm{~m}$. Of high.

The type of applied design was that of complete blocks at random. 
El que no ha nacido para servir, no sirve para viviroo

8 experimental portions were used: Four for the initial stage with $21 \%$ of raw Protein and four for the finish phase with $18 \%$ of PC.

The rehearsal portions were made up of the following ingredients: yellow Corn, wheat flour, sorghum flour, polvillo of rice, soya flour, fish flour, flour of bones, salt yodada, vitamins, metionina, furidona and liver flour of bovine. The portions witness didn't contain liver flour.

\section{BIBLIOGRAFÍA}

1. BOLTON. Nutrición Aviar. Traducido por Elías Fernández González. Editorial Acribia. Zaragoza. España. 1962. pp 75

2. HERNÁNDEZ, B. Manual de Nutrición y alimentación del ganado. Primera edición. Publicaciones de extensión agraria. Madrid, España. 1980. pp 9,10,15

3. MORRISON, F. Compendio de alimentación de ganado. Editorial Uteha. México. 1977. pp. 385-386.

4. PICCIONI, M. Diccionario de alimentación animal. Editorial Acribia. Zaragoza, España. 1970. pp. 357-359.

5. ROSERO, M. Utilización de tres niveles de harina de hígado de bovino como fuente de proteína en la alimentación de pollos broilers. Tesis doctoral. Cuenca, Ecuador. 1993.

6. SALCEDO, E. Técnicas y prácticas modernas en la cría de la gallina. Editoriales Mexicanos Unidos. México. 1985. pp. 172-173.

7. SCOTT, YOUNG Y NESHEIM. Alimentación de las aves. Editorial Gea. España. Primera edición. 1973. pp 406-431.

\section{* Catedrático de Clínica Veterinaria y Biometría}

